\title{
(Research Article) \\ Influence of Fly Ash Particles on Surface Roughness and Friction Coefficient of Magnesium Metal Composites
}

\author{
R. S. Fono-Tamo ${ }^{{ }^{*}}$ \\ ${ }^{1 *}$ Department of Mechanical Engineering, Papua New Guinea University of Technology, Lae, 411, Papua New Guinea
}

\begin{abstract}
Surfaces of magnesium metal composites (MMC) with fly ash (FA) particles embedment processed through friction stir processing (FSP) was subjected to friction and roughness test. The friction stir processing development was done with 3 passes at $1200 \mathrm{rpm}$. The investigation was conducted via a profilometer dotted with a diamond stylus at a speed of $0.2 \mathrm{~mm} / \mathrm{s}$ for the surface roughness test. The sliding friction test was carried out using a pin-on-disk tribometer under varying load condition. The coefficient of friction (COF) was investigated under 1 and $10 \mathrm{~N}$ loads at a constant speed at $70 \%$ humidity. A digital Vickers Hardness tester helped find the hardness at various locations of the processed surface. The determined surface roughness parameters are $\mathrm{Ra}=3.21 \mu \mathrm{m}, \mathrm{Rz}=18.47 \mu \mathrm{m}$ and $\mathrm{Rmax}=22.45 \mu \mathrm{m}$. There is a regular increase in hardness from the beginning to the end of the process with average values as $69.34,71.44$ and 74.03 for the beginning, middle and end of the work piece respectively. The coefficient of friction varies considerably with the applied load. For each load, there is a fluctuation at the early stage of the experiment before a seeming stability of the coefficient of friction is observed. The derived COF are 0.82925 and 0.27459 for 1 and $10 \mathrm{~N}$ loads respectively. It is shown that including fly ash particles into magnesium substrate affects the initial structure of the based metal.
\end{abstract}

Keywords: Coefficient of Friction; fly ash; Friction Stir Processing; Magnesium Metal Composites; Surface Roughness

\section{Introduction}

Magnesium is qualified as the lightest structural metal. Magnesium alloys falls within the metal matrix composites (MMCs) and when compared to other metals like aluminium, titanium and stainless steel, they are 33\%,61\% and $77 \%$ lighter respectively. Such a light property makes magnesium a suitable replacement candidate for other metals [1 - 2]. Although conventional alloying practice has been traditionally used to reinforce magnesium alloys, Mordike and Ebert [3] found that such practice cannot ensure certain properties and as such fibre and particle reinforcement must be used. Friction stir processing (FSP) is an upcoming technique of grain refinement [4]. It is a technique derived from the FSW (Friction Stir Welding) technology developed in 1991 by Wayne Thomas from the Welding Institute (TWI Ltd.) in Cambridge [2]. It is a solid state process whereby reinforcing particles are inserted into the structure of a material thus creating a composite with enhanced properties $[1,5]$. Traditionally, grain refinement in materials could be

*Corresponding Author: e-mail: romeo.fono-tamo@pnguot.ac.pg ISSN 2320-7590

(C) 2020 Darshan Institute of Engg. \& Tech., All rights reserved achieved using severe plastic deformation (SPD) methods nemely, high pressure torsion (HPT), equal channel angular pressing (ECAP) and accumulative roll bonding (ARB) [6]. It has been revealed from studies that adding nanoreinforcements on magnesium alloys contribute to the enhancement of its mechanical properties without any adverse effect on the ductility [6]. SiC nanoparticles were added to AZ31 alloy using FSP by Haghani et al. [5], they found that adding reinforcing materials causes reduction in the size of the grains, uniformity of structure and increase in the hardness of material. $\mathrm{SiC}$ nanoparticles distributed uniformly through the AZ31 alloy. Deepan et al. [7] varied FSP parameters while adding $\mathrm{SiC}$ powders of nanosize into the RZ5 substrate. Their result showed that uniform distribution of nano $\mathrm{SiC}$ reinforcements was successfully achieved in the metal matrix. The abrasive wear property of the $\mathrm{Mg}-\mathrm{SiC}$ nanocomposite was evaluated with respect to the FSP process parameters. Process parameters such as the number of pass [5, $6,8]$ and the shape of the tool [9] are critical in achieving the desired result during FSP [10]. Bodurin et al. [11] noted three broad groups of reinforcing materials used in the development of MMCs and these are synthetic ceramic particulates, industrial wastes and agro waste by-products. So, a brand new generation of hybrid MMCs is being developed with the use 
of industrial and agro waste derivatives as replacement to synthetic reinforcement. The advantages offered by the industrial and agro waste derivatives when used in the production of MMCs include low cost, accessibility, low density as well as low environmental pollution. Fly ash is one of the industrial waste which has been extensively investigated as reinforcement material in MMC with a wide range of production methods including FSP. Due to the increase of possible application of magnesium alloys in automobile, sport equipment, communication engineering [3], as well as in military [1,12-13], in medical field [1, 14], in aviation [1]. It has become critical to understand the correlation between the surface roughness and the friction coefficient of the developed magnesium alloy with fly ash as reinforcement.

This work therefore applies friction stir processing method to develop fly ash reinforced magnesium alloy and establishes how the surface roughness of such alloy can subsequently affect its coefficient of friction. This is important especially if such alloys will be used for orthopedic implants.

\section{Materials and Method}

This study adopted AZ61 $\mathrm{Mg}$ alloy surface plates as substrate in order to fabricate the MMC. A list of chemical elements usualy in AZ61 Mg alloy is seen in Table 1. Vshaped $3.5 \mathrm{~mm}$ deep grooves were scarred into the substrate and filled with fly ash powder. The processing tools were hardened to 52 HRC while machined from H13 tool steel They also had a Tilt Angle of zero, undergoing three passes in order to properly compress the powder across the substrate surface throughout the experiments. The FSP was achieved on 5 -Axis FSW machine with $1200 \mathrm{rpm}$ and $20 \mathrm{~mm} / \mathrm{min}$ as tool rotational and travel speed respectively. The process was carried on under $20 \mathrm{kN}$ applied load as perpendicular and lateral forces on a securely clamped workpiece of $650 \times 265$ $\times 25 \mathrm{~mm}^{3}$ dimensions. The microstructure, microhardness and friction properties were evaluated thereafter.

Microstructural surface survey of the MMCs was achieved via optical microscope. Samples preparation was according to the standard including the normal and sequential grinding process, polishing stage and etching with acetic picric solution. Recorded micrographs from the beginning, middle and end of the plate after FSP set. An Anton Paar GmbH standard tribometer vesrsion 7.3.13 was useful in assessing friction properties. In this machine, a single ball runs in a single way mode at a linear speed of $4.97 \mathrm{~cm} / \mathrm{s}$ in an ambient temperature of $25^{\circ} \mathrm{C}$. The experimental loads were $1 \mathrm{~N}$ and $10 \mathrm{~N}$ respectively and the running time averaged 15 minutes. Plots of the friction coefficient with its generated values were displayed. Digital Vickers hardness (HV) tester HXD$1000 \mathrm{TM} / \mathrm{LCD}$ helped determine microhardness at a load of $4.9 \mathrm{~N}$ for $15 \mathrm{~s}$. Tested specimens were source from relevant portions of the fsped surface composites.
Surface roughness was conducted according to the description made by FonoTamo and Tien-Chien [15] whereby a profilometer (Hommel-Etamic T8000) mounted with a diamond stylus served the purpose of determining the parameters. This was achieved via a connection to a desktop computer with an integrated software able to plot the roughness profiles. Transverse length of $2 \mathrm{~mm}$ and speed of $0.2 \mathrm{~mm} / \mathrm{s}$ were deemed suitable as experimental condition. Proper representation was achieved by replicating the test 3 times for each sample and the average calculated.

Table 1. Chemical elements found in AZ61 Mg substrate

\begin{tabular}{|l|l|l|l|l|l|l|l|}
\hline Weight $\%$ & $\mathrm{Mg}$ & $\mathrm{Al}$ & $\mathrm{Fe}$ & $\mathrm{Si}$ & $\mathrm{Mn}$ & $\mathrm{Ca}$ & $\mathrm{Zn}$ \\
\hline AZ61 & Bal & 6.17 & 0.005 & 0.04 & 0.3 & 0.0012 & 0.75 \\
\hline
\end{tabular}

\section{Results and discussions}

An exhibit of the process magnesium alloy surface is presented in Figure. 1.

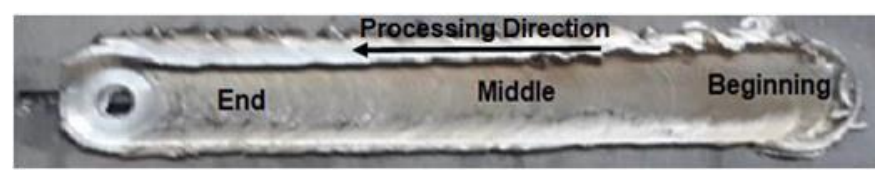

Figure. 1. Friction stir processed sample

The processing direction is from the right to the left. In the rotation process of the tool probe and the tool shoulder coupled with the downward force on the tool, heat is generated which in turn softens the material. The softened material then fills the cavity at the rear of the tool and at the same time is subjected to severe plastic deformation which further lead to a significant refinement of processed zone and consequently the reinforcement material in the groove. Figure. 2 shows the micrographs of the alloy at various stages in the processing direction. The beginning, middle and end being $\mathrm{C}, \mathrm{B}$ and $\mathrm{A}$ respectively. Good interfacial bonding is revealed in the microstructural visualisation between matrix phase and reinforcement. Banerjee et. al, [16] had similar observation in their work on dry sliding tribological behavior of AZ31-WC nano-composites. It is noticeable in the micrographs that the particle size of the ash is further reduced at the end of the process as compared to the beginning. This is attributed to frictional heating and severe plastic deformation induced by the rotating tool which lead to the formation of dynamically recrystallized grains and the dispersing of the inserted ash particles in stir zones of the Mg-based composites. Furthermore, better ash particle distribution in the magnesium substrate at the end than at the 
beginning of the process is observed. Moreover, in the same study by [16] where the microstructure of $\mathrm{Nano}_{-} \mathrm{SiO}_{2}$ particulate reinforced $\mathrm{AZ} 31-\mathrm{Mg}$ based composites made by FSP was analysed, uniform dispersion of $\mathrm{SiO}_{2}$ particles after 1 pass, what noticed along some local inhomogenised areas of particles. Better homogenization was achieved after 4 passes. So, for further analysis that is for surface roughness and friction testing samples were acquired from the end of process because of the even distribution and better grain refinement achieved.
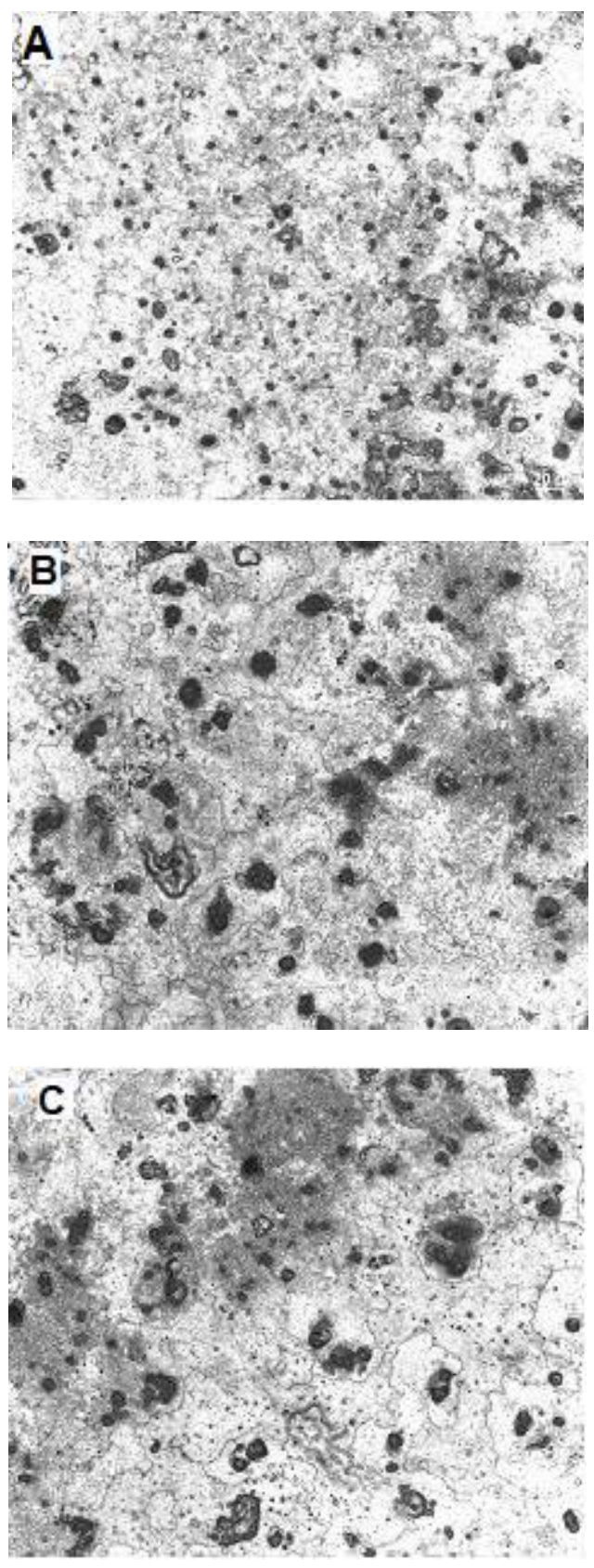

Figure 2. Optical micrographs of the processed surface composite A. End, B. middle and C. Beginning.
According to Fono-Tamo and Tien-Chien [15], roughness plays an important role in understanding the interaction of an object with its environment. Furthermore, rough surfaces often wear faster and have higher friction coefficient than smooth surfaces [17]. Figure. 3. is the representation of the surface behavior profile of the alloy taken at the end of the process where it is believed quality alloy is achieved based on grain refinement and grain distribution

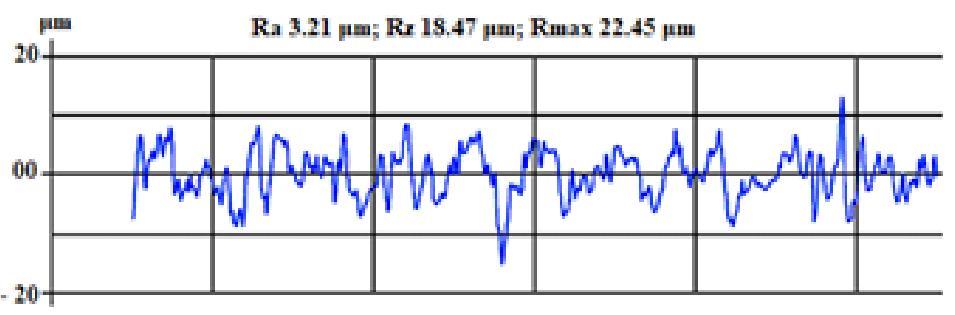

Figure 3. Typical surface roughness profile

The derived values for average roughness (Ra), Average Maximum height of the Profile (Rz) and Maximum Roughness Deph (Rmax) are presented as 3.21, 18.47 and $22.45 \mu \mathrm{m}$ respectively. There are reports in the literature that narrow height distribution is associated with smoother surface. At the same time, the application of the concerned surface is of essence and that is why a rough surface for certain application may be smooth for another one. In the current study, a Ra value of $3.21 \mu \mathrm{m}$ is comparable to those arrived at $(2.7$ and $6.3 \mu \mathrm{m})$ by Sealy et al. [18]. They used laser shock peening to adjust the surface integrity of a biodegradable $\mathrm{MgCa} 0.8$ alloy to be used for orthopedic implants. The average laser power was $3 \mathrm{~W}$ and the dent overlap was $25 \%$ and $75 \%$. So at $3 \mathrm{~W}-25 \% \mathrm{Ra}=2.7 \mu \mathrm{m}$ while at $3 \mathrm{~W}-75 \%, \mathrm{Ra}=6.3 \mu \mathrm{m}$. These values were deemed acceptable for orthopedic inplant materials. Furthermore, Figure 4. Shows how hardness average value increases as one moves from the beginning to the end of the process.

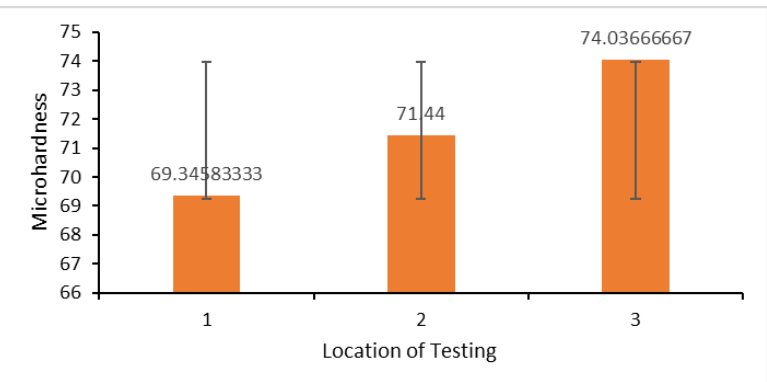

Figure 4. Microhardness values at various regions of the process

Including nanoparticles in matrix phase create substantialal changes in mechanical properties like hardness [16]. Hardness value of a composite indicates the contribution of reinforcements in base matrix. Tool rotation (1200 rpm) as well as transverse speed contribute in obtaining the desired 
strength and structure in the composite [19]. Homogenously distributed particles at the end of the process significantly contribute to strengthening the composite and higher hardness achieved sequel to grain refinement at higher tool rotational speed.

Determined coefficient of friction for 1 and $10 \mathrm{~N}$ load are shown in Figure. 5 and their mean are 0.82925 and 0.27459 respectively. It can be observed from the plots that there is a stability towards the end as compared to the beginning. This might be due to wear debris accumulated on the surface of the wear track thus providing a kind of smooth protective coating reducing the wear of the base material. The high $\mathrm{COF}$ observed in $1 \mathrm{~N}$ might be due to the fact that the load is not high enough to generated as much wear debris as does load $10 \mathrm{~N}$ at the beginning of the process, thus there is a continuous degradation of the material due to continuous contact with the base material till the end of the experiment. There is often a gradual decrease of friction coefficient with increase in applied load. This load also generates flash temperature due to frictional heating. As a result, oxide layer is created between pin surfaces and counter disk [16]. This is unlike load $10 \mathrm{~N}$ which exhibit an increase in cof for a while then continuous stability. This can also be attributed to the increase of the number of asperities and consequently increase in resistance to wear attained by the rotating ball of the tribometer at the surface of the sample as load increase. The friction coefficient between a metal and another metal should be approximately the range from 0.6 to 1 without lubrication says Hino et al. [20]. Thus, the acquired coefficient of friction in this study are in order. These values also fall within a set of coefficient of friction values recorded by Hussein et al. [21] as suitable for metallic biomaterial for joint replacement, dental roots and orthopedic fixation.

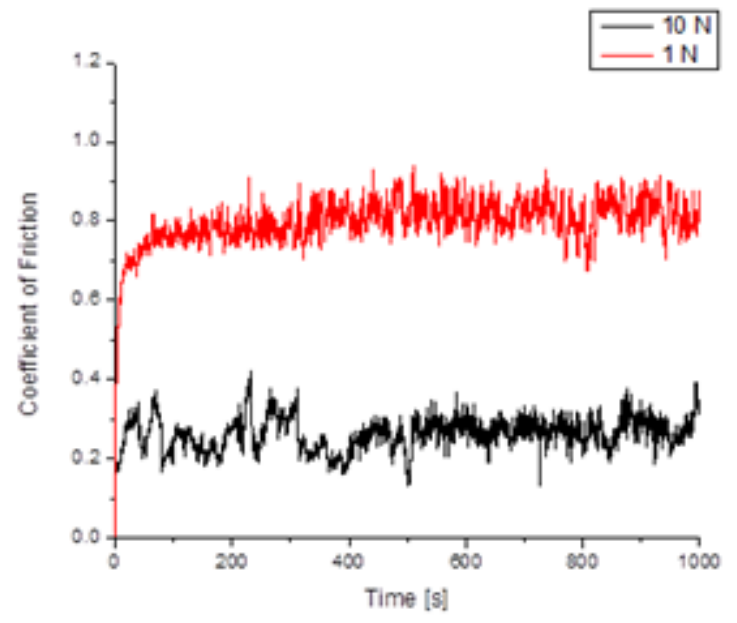

Figure 5. Friction coefficient at 1 and $10 \mathrm{~N}$ load.

A shortfall of MMC is corrosion and care need to be taken when considering it for medical application. For instance, the effect of the use of Polydopamine as intermediate layer was tested to evaluate the degradation behavior of $\mathrm{Mg}$ AZ31 samples when immersed in Hank's solution by Carangelo et al. [22]. It was observed that the deposited PDOPA intermediate coating between the $\mathrm{Mg}$ substrate and the organic coating helped decreased the degradation rate of AZ31 magnesium samples during the long-term exposure in the simulated body fluid. This is an illustration that ageing of MMC can be influenced when adequate measures are taken but this aspect was not considered in this paper.

\section{Conclusion}

This study has shown that friction stir processing is a viable technique to develop magnesium matrix composites with fly ash powder as reinforcement. Even distribution of the powder as well powder refinement in the matrix is achieved. The determined surface roughness in comparable to those found in literature for materials used in orthopedic implants. The derived coefficient of friction is affected by the presence of fly ash powder into the matrix as well as the load increase. Thus, while at a low load of $1 \mathrm{~N}$ the coefficient of friction value is high, at a higher load the same coefficient of friction is lower. Again, the coefficient of friction values are comparable with those found in literature for metal alloys for biomedical application. Clearly, the inclusion of coal fly ash particle in the magnesium substrate by FSP improves the studied properties of the developed composites.

\section{Acknowledgements}

The author is thankful to the Centre for Nanomechanics and Tribocorrosion as well as the Department of Mechanical Engineering Science of the University of Johannesburg for making the equipments available for the successful conduct of this work.

\section{References}

1. M. Gupta and W.L.E.Wong, Magnesium-based nanocomposites: Lightweight materials of the future. Materials Characterization Vol.105, pp. 30-46, 2015.

2. J. Iwas zko, K. Kudła, K. Fila and M. Strzelecka, The Effect Of Friction Stir Processing (Fsp) On The Microstructure And Properties Of Am60 Magnesium Alloy, Arch. Metall. Mater., Vol. 61, No 3, pp. 1555-1560, 2016, DOI: 10.1515/amm-20160254

3. B.L. Mordike, T. Ebert, Magnesium: Properties applications - potential, Materials Science and Engineering A, Vol.302, pp.37-45, 2001.

4. S. Rathee, S. Maheshwari and A. N. Siddiquee Issues and strategies in composite fabrication via friction stir processing: A review, Materials and Manufacturing Processes, 2017, DOI: 10.1080/10426914.2017.1303162

5. Haghani , S. H. Nourbakhsh, M. Jahangiri, 
Investigation of Mechanical Property and Microstructure of Nanocomposite AZ31/SiC Fabricated by Friction Stir Process, Int J Advanced Design and Manufacturing Technology, Vol. 9, No. 2, pp. 27-34, 2016

6. Raja and V. Pancholi (2017):" Effect of friction stir processing on tensile and fracture behaviour of AZ91 alloy". Journal of Materials Processing Tech. Vol.248, pp. 8-17, 2017.

7. M. Deepan, C. Pandey, N. Saini, M. M. Mahapatra and R. S. Mulik (2017):" Estimation of strength and wear properties of $\mathrm{Mg} / \mathrm{SiC}$ nanocomposite fabricated through FSP route". J Braz. Soc. Mech. Sci. Eng. Vol. 39, pp.4613-4622, 2017, DOI 10.1007/s40430-017-0757-1

8. M. Jamilia, A. Zarei-Hanzakia, H. R. Abedia, P.Minárikb, R. Soltanic (2017):" The microstructure, texture, and room temperature mechanical properties of friction stir processed $\mathrm{Mg}$ Y-Nd alloy" Materials Science and Engineering A, , pp. 18-44, 2017.

9. Gupta, P. Singh, P. Gulaticand D. K. Shuklad (2015):" Effect of Tool rotation speed and feed rate on the formation of tunnel defect in Friction Stir Processing of AZ31 Magnesium alloy". 4th International Conference on Materials Processing and Characterization, Materials Today: Proceedings 2 ( 2015 ) $3463-3470$, doi: 10.1016/j.matpr.2015.07.322

10. B.M. Darras, M.K. Khraisheh , F.K. Abu-Farha, M.A. Omar (2007):" Friction stir processing of commercial AZ31 magnesium alloy". Journal of Materials Processing Technology 191 (2007) 77-81

11. M. O. Bodunrin, K. K. Alaneme and L. H. Chown (2015)"Aluminum matrix hybrid composites: a review of reinforcement philosophies; mechanical, corrosion and tribological characteristics". Journal of Materials Research and Technology, Vol.4, No. 4, pp.434-445, https://doi.org/10.1016/j.jmrt.2015.05.003

12. M. F. Abdullah, S. Abdullah, M. Z. Omar, Z. Sajuri and R. M. Sohaimi, Failure observation of the AZ31B magnesium alloy and the effect of lead addition content under ballistic impact, Advances in Mechanical Engineering,Vol.7. No. 5, pp. 1-13, 2015, DOI: $10.1177 / 1687814015585428$

13. S. N. Mathaudhu and E. A. Nyberg (2014): "Magnesium alloys in u.s. Military applications: past, current and future solutions". The Minerals, Metals \& Materials Society. Published 2014 by John Wiley \& Sons, Inc
14. W.R. Zhou, Y.F. Zheng, M.A. Leeflang and J. Zhou (2013): Mechanical property, biocorrosion and in vitro biocompatibility evaluations of $\mathrm{Mg}-\mathrm{Li}-(\mathrm{Al})-$ (RE) alloys for future cardiovascular stent application". Acta Biomaterialia 9: 8488-8498

15. R. S. Fono-Tamo and Jen Tien-Chien (2017)" Effect of Ingredient Particle Sizes on Surface Roughness Characteristics of PKS Brake Lining". ASME 2017 International Mechanical Engineering Congress and Exposition 14, Tampa, Florida, USA, November 39, 2017

16. S. Banerjee, S. Poria, G. Sutradhar, P. Sahoo, Dry sliding tribological behavior of AZ31-WC nanocomposites, Journal of Magnesium and Alloys, Vol.7, pp 315-327,2019 https://doi.org/10.1016/j.jma.2018.11.005

17. I. Chang, Y. N. Wang, H. R. Pei, C. J. Lee, X. H. $\mathrm{Du}$,

18. J. C. Huang Microstructure and Mechanical Properties of Nano-ZrO2 and Nano-SiO2 Particulate Reinforced AZ31-Mg Based Composites Fabricated by Friction Stir Processing, Key Engineering Materials Vol. 351, pp. 114-119, 2007.

19. M.P. Sealy, Y.B. Guo, R.C. Caslaru, J. Sharkins, D. Feldman (2016)"Fatigue performance of biodegradable magnesium-calcium alloy processed by laser shock peening for orthopedic implants". International Journal of Fatigue 82: 428-436, http://dx.doi.org/10.1016/j.ijfatigue.2015.08.024

20. Srinivasan Murugan, Quy Bau Nguyen and Manoj Gupta, Synthesis of Magnesium Based Nanocomposites,in; Magnesium - The Wonder Element for Engineering/Biomedical Applications DOI: http://dx.doi.org/10.5772/intechopen.84189

21. Makoto Hino, Koji Murakami, Atsushi Saijo, Shuji Hikino and Teruto Kanadani (2011) "Friction and Wear Properties on AZ91D Magnesium Alloy Treated by Anodizing from Phosphate Electrolytic Solution", Materials Transactions 52 (9): 1752 to 1758, doi:10.2320/matertrans.L-M2011816

22. Mohamed A. Hussein, Abdul Samad Mohammed and Naser Al-Aqeeli (2015)," Wear Characteristics of Metallic Biomaterials: A Review", Materials 8: 2749-2768; doi:10.3390/ma8052749

23. Carangelo, A. Acquesta and T. Monetta, Durability of AZ31 magnesium biodegradable alloys polydopamine aided. Part 2: Ageing in Hank's solution, Journal of Magnesium and Alloys Vol.7, pp. 218-226, 2019.

https://doi.org/10.1016/j.jma.2019.04.003

\section{Biographical notes}

R. S. Fono Tamo has received his Ph.D. from Obafemi Awolowo University in Mechanical Engineering. He is lecturer in the Department of Mechanical Engineering of Papua New Guinea University of Technology, Lae, Papua New Guinea. His research interest includes Design and Manufacturing, Material Development and Characterisation, Tribology. 